\title{
Low temperature characteristics of germanium whiskers
}

\author{
A.A.Druzhinin ${ }^{*}{ }^{* *}$, I.P.Ostrovskii ${ }^{*} * *$, Yu.N.Khoverko ${ }^{*}, * *$, \\ N.S.Liakh-Kaguy", A.M.Vuytsyk* \\ "Lviv Polytechnic National University, \\ 1 Kotlyarevski Str., 79013 Lviv, Ukraine \\ *: International Laboratory of High Magnetic Fields and Low \\ Temperatures, Wroclaw, Poland
}

Received November 26, 2013

\begin{abstract}
Magnetophonone oscillations of magnetoresistance in heavily doped $n$-Ge whiskers with impurity concentration that corresponds to metal-insulator transition were studied in the temperatures range $4.2-70 \mathrm{~K}$ in continuous and pulse magnetic fields up to $14 \mathrm{~T}$ and $35 \mathrm{~T}$, respectively. The influence of uniaxial compressive and tentative strain on the magnetophonon oscillations of longitudinal and transverse magnetoresistance of $n-\mathrm{Ge}$ whiskers were studied, the intervalley transitions were determined, phonon energy as well as the effective masses of light and heavy electrons in $n-G e$ whiskers were estimated. Ge whiskers were used for creation of strain-temperature sensors, operating in high magnetic fields and at low temperatures.
\end{abstract}

Исследованы магнитофононные осцилляции магнитосопротивления в сильнолегированных нитеподобных кристаллах (HK) Gen-типа проводимости с концентрацией примеси, что отвечает переходу металл-диэлектрик, в интервале температур 4,2-70 $\mathrm{K}$ в непрерывных и импульсных магнитных полях с индукцией 14 Тл и 35 Тл соответственно. Изучено влияние одноосной деформации сжатия и растяжения на магнитофононные осцилляции поперечного и продольного магнитосопротивления, определены междолинные переходы, оценены энергии фононов и әффективные массы тяжелых и легких электронов в $\mathrm{HK} n-\mathrm{Ge}$. Предложено HК германия для создания на их основе низкотемпературных сенсоров деформации-температуры, работоспособных в сильных магнитных полях.

Низькотемпературні характеристики ниткоподібних кристалів германію. А.О.Дру жинін, І.П.Островсъкий, Ю.М.Ховерко, Н.С.Ллх-Кагуй, А.М.Вуйцик.

Досліджено магнітофононні осциляції магнітоопору в сильнолегованих ниткоподібних кристалах (НК) Ge $n$-типу провідності з концентрацією домішки, що відповідає переходу метал-діелектрик, в інтервалі температур 4,2-70 $\mathrm{K}$ в неперервних та імпульсних магнітних полях з індукцією 14 Тл та 35 Тл відповідно. Вивчено вплив одновісної деформації стиску та розтягу на магнітофононні осциляції поперечного і поздовжнього магнітоопору, визначено міждолинні переходи, оцінено енергії фононів та ефективні маси важких та легких електронів в HК $n$-Ge. Запропоновано HК германію для створення на їх основі низькотемпературних сенсорів деформації-температури, працездатних в сильних магнітних полях.

\section{Introduction}

Magnetophonon resonance has been extensively studied in semiconductor crystals
[1-7], because this study made it possible to find out the nature of the electron-phonon interaction and also to investigate band structure of crystals. Now this phenomenon 
is in the field of many researches [8-13]. However, unlike previous studies, which investigated mostly solid samples, the focus of current research are quantum wells and superlattices of typical semiconductor crystals: $n$-Ge $[8,9], n$-GaAs, GaAlAs $[8,10]$, graphene 11-13].

From this point of view it is interesting to study magnetophonon resonance in $\mathrm{Ge}$ whiskers. There were founded a number of effects, atypical for bulk samples: lattice parameter changing [14], the shift of the fundamental optical absorption bands in the shortwave region of the spectrum and the appearance of new luminescence bands atypical for bulk crystals associated with exposure of Laplace compressive on whiskers [15]. It should be noted that the issue of the strain impact on the magnetophonon resonance behaviour in semiconductors has been studied in only few publications [10, 12]. At the same time, this issue is very important for nanoelectronic devices, which virtually can not avoid the influence of strain.

Low-temperature piezoresistance of heavily doped germanium whiskers with $n$ - and $p$-type conductivity were studied in previous investigations [16]. According to results of studies Ge whiskers doped to concentrations in the vicinity to metal-insulator transition at low temperatures have a high gauge factor. That allows using them as sensitive elements of thermal and mechanical sensors for cryogenic energetic and space research. However, the specifics of application for pressure and temperature sensors based on germanium whiskers, mainly associated with their using in the high magnetic fields. From this point of view, the studies of influence of the magnetic field as destabilizing factor on sensor operating in the range of cryogenic temperatures are great interesting.

The influence of uniaxial tensile and compressive strain on the magnetoresistance of heavily doped germanium whiskers with $n$ - and $p$-type conductivity are shown in [16]. During the research of $n-\mathrm{Ge}$ whiskers there was found that uniaxial tensile strain stimulates an appearance of magnetoresistance oscillations in the transverse magnetic field, while the effect of uniaxial compressive strain leads to oscillations of the magnetoresistance in the longitudinal magnetic field, due to the redistribution of electrons between the bottoms of the conduction band of $n$-type conductivity germanium under strain. However, this paper studies magne- toresistance in magnetic fields up to $14 \mathrm{~T}$, which experienced only two oscillating peaks, so it was difficult to interpret obtained results. It is necessary to research magnetoresistance in high magnetic fields up to $35 \mathrm{~T}$, which will occur more oscillating peaks that gives an opportunity to determine the period of recurrence. There were not classified intervalley transitions and phonon energies were not calculated in [16].

The purpose of this paper is to summarize and clarify the behaviour of the $n-\mathrm{Ge}$ whiskers magnetoresistance under uniaxial tensile and compressive strain in the high magnetic fields with induction up to $35 \mathrm{~T}$ to determine the nature of magnetophonon interaction type, intravalley and intervalley transition types that correspond to the appearance of oscillating peaks on field dependence of the magnetoresistance on the basis of results comparison with known theoretical and experimental data.

\section{Experimental}

Ge whiskers grown by chemical transport reactions in the gas phase in closed system. The crystals were in the form of hexagonal prisms with the longitudinal axis of the crystallographic directions $<111\rangle$ and diameters of $10-60 \mu \mathrm{m}$. Ge $n$-type conductivity microcrystals doped with $\mathrm{Sb}$ during growth. As proponents of growth treated with admixture of gold and platinum. All samples were poorly compensated $(k<0.01)$ [17]. The impurity concentration in the crystals corresponded to concentrations close to the metal-insulator transition (MIT). Electrical contacts created by pulse welding silver microwire with microcrystals, contacts were ohmic over the entire range of studied temperatures. As it is difficult to create Hall contacts to whiskers for Hall research to determine the concentration of impurities due their small size we use resistivity at room temperature for their characterization. If weak compensation the resistivity can roughly estimate the concentration of donor impurities in the crystal. Proximity to PHC correspond samples with a resistivity $\rho_{300 K}=0.02 \mathrm{Ohm} \cdot \mathrm{cm}$. Uniaxial mechanical stress of the Ge whiskers was established by fixing microcrystals on the substrate due to the difference of thermal expansion coefficients of $\mathrm{Ge}$ and the substrate material. Methods for creating uniaxial mechanical stress and strain values obtained at different temperatures are given in $[8,9]$. Specifically, the substrate of quartz and aluminium, on which whiskers 
were fixed provide, respectively, the relative strain $\varepsilon=1.37 \cdot 10^{-3}$ and compressive $\varepsilon$ $=-4.38 \cdot 10^{-3}$ at a temperature of $4.2 \mathrm{~K}$.

Magnetoresistance measurements of the of heavily doped $n-\mathrm{Ge}$ whiskers with $\rho_{300 \mathrm{~K}}=0.008-0.022 \mathrm{Ohm} \cdot \mathrm{cm}$ was performed on Bitter magnet in fields with induction up to $14 \mathrm{~T}$ in the temperature range $4.2-70 \mathrm{~K}$ and in magnetic fields with induction up to 35 Tesla on the pulsed magnet at the temperature of liquid helium in the International laboratory of High Magnetic fields and Low Temperatures (Wroclaw, Poland). In all the samples the current was passed along the direction [111] and the magnetic field in the directions: $B\|[111], B\|[110]$ and $B \perp[111]$.

\section{Results and discussion}

Transversal magnetoresistance of heavily doped $n$-type conductivity Ge whiskers with a resistivity $\rho_{300 \mathrm{~K}}=0.008-0.022 \mathrm{Ohm} \cdot \mathrm{cm}$ was investigated at temperatures of liquid helium as without strain (Fig. 1), as with tensile and compressive strains (Fig. 2). As shown in Fig. 1 and Fig. 2, the dependences of the magnetoresistance in $B \perp[111]$ for unstrained $n-\mathrm{Ge}$ whiskers detected oscillation maxima only for samples with a resistivity $\rho_{300 \mathrm{~K}}=0.01 \mathrm{Ohm} \cdot \mathrm{cm}$, and for samples with a resistivity $\rho_{300 \mathrm{~K}}=0.02 \mathrm{Ohm} \cdot \mathrm{cm}$ oscillating magnetoresistance maxima appear only after strain (Fig. 2). Detected relative magnetoresistance oscillation maxima periodic to inverse field with a period $\Delta(1 / B)=$ $0.04 \mathrm{~T}^{-1}$ for free and $\Delta(1 / B)=0.041 \mathrm{~T}^{-1}$ for tensile strained whiskers. Based on the ratio $\Delta(1 / B)=e / m^{*} \omega_{p}$, where $e-$ electron charge , $m^{*}-$ effective mass of an electron in a certain valley, $\omega_{p}-$ phonon frequency, with which there intervalley of intravalley electron transition occur electron transitions in unstrained $\mathrm{Ge}$ whiskers were specified. These maxima of the magnetophonon oscillations due to transitions between Landau levels in the valley with the cyclotron effective mass $m_{L}=0.082 m_{e}$ with the transverse optical phonon in the $L$-point of the Brillouin zone with energy $E_{T O}=$ $36.15 \mathrm{meV}$ [18].

Relative strain with $\varepsilon=1.37 \cdot 10^{-3}$ a application leads to a unsibnificant decrease in the frequency of optical phonon [19] $E_{T O}=$ $36.05 \mathrm{meV}$, which is indicated in a little change of the period $\Delta(1 / B)=0.041 \mathrm{~T}^{-1}$. Research has shown the influence of the strain on the Ge whiskers resistance tem-

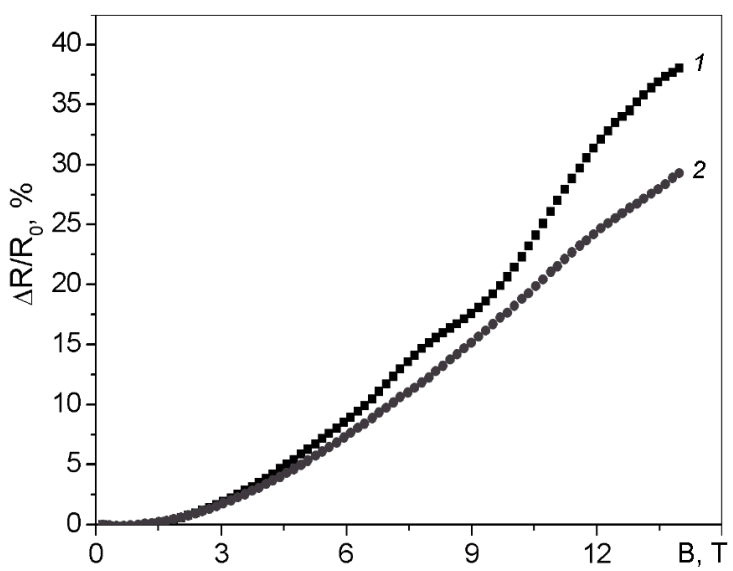

Fig. 1. Magnetoresistance of unstrained $n$-type Ge whiskers in the direction $J \|[111], B \perp[111]$ at temperature $4.2 \mathrm{~K}$ with different resistivity $\rho_{300 \mathrm{~K}}, \mathrm{Ohm} \cdot \mathrm{cm}: 0.01$ (1); 0.008 (2).

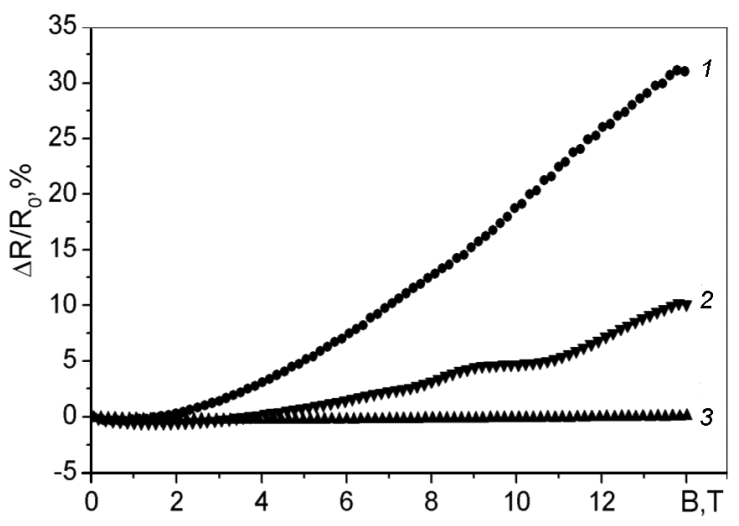

Fig. 2. Magnetoresistance of $n$-type Ge whiskers with resistivity $\rho_{300 \mathrm{~K}}=0.02 \mathrm{Ohm} \cdot \mathrm{cm}$ in the direction $J \|[111], B \perp[111]$ at temperature $4.2 \mathrm{~K}$ : unstrained crystal (1); under uniaxial tensile strain $\varepsilon=1.37 \cdot 10^{-3}$ rel.un. (2); under uniaxial compressive strain $\varepsilon=-4.38 \cdot 10^{-3}$ rel.un. (3).

perature dependence (Fig. 3), the strain does not change the nature of the resistance temperature dependence (see curves 1 and 3). Thus, we can assume that the interpretation of detected magnetophonon oscillations is the same for unstrained and tension strained samples. Based on the researches we can make one more conclusion about the evidence of one of the characteristics: magnetophonon resonance period caused by the same intravalley transition does not depend on the concentration of charge carriers.

Compressive strain $\varepsilon=-4.38 \cdot 10^{-3}$ (curve 2 in Fig. 3) application leads to the 


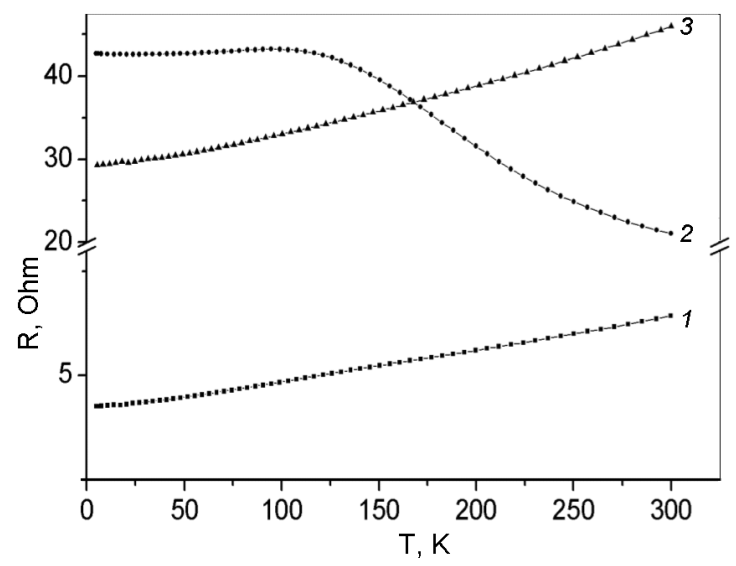

Fig. 3. Temperature dependences of resistance for n-type Ge whiskers with resistivity $\rho 300 \mathrm{~K}=0.02 \mathrm{Ohm} \cdot \mathrm{cm}$ : unstrained crystal (1); under uniaxial compressive strain $\varepsilon=$ $-4.38 \cdot 10-3$ rel.un. (2); under uniaxial tensile strain $\varepsilon=1.37 \cdot 10-3$ rel.un. (3).

transfer of the sample through the metal-insulator transition, as a result the temperature dependence of the resistance change from metal to semiconductor. In this case, under the influence of strain degeneracy is removed, and the isoelectron valleys split into valleys with light and heavy cyclotron effective mass of the electron, corresponding to the direction of carriers in the crystal. Thus, for the direction [111] cyclotron effective mass of heavy electrons $m_{H}=$ $0.207 m_{e}$, and for light $m_{L}=0.082 m_{e}$.

As shown in Fig. 2, there no oscillations of the magnetoresistance in the direction $J \|[111], B \perp[111]$ in compressive strained samples. Instead, tension strain leads to the large magnetophonon oscillations of the magnetoresistance towards $J\|B\|[111]$. On Fig. 4 it is shown magnetoresistance towards $J\|B\|[111]$ for $n$-type conductivity germanium whiskers with a resistivity $\rho_{300 \mathrm{~K}}=$ $0.022 \mathrm{Ohm} \cdot \mathrm{cm}$ in a magnetic field $0-14 \mathrm{~T}$ under uniaxial compressive strain $\varepsilon=$ $-4.38 \cdot 10^{-3}$ at a temperature of $4.2 \mathrm{~K}$. On the dependence of the magnetoresistance in the direction $J\|[111], B\|[110]$ in a magnetic field with induction up to $14 \mathrm{~T}$ four oscillating peaks (Fig. 4, curve 1) were detected. For the experiment in which $J\|B\|[111]$ on Fig. 4 (curve 2) there are four oscillation maxima, and in impulse magnetic fields shown on Fig. 5 (in pulsed fields up to $35 \mathrm{~T})$ - six oscillating peaks.

Detected magnetoresistance oscillation maxima in the experiment in which $J\|B\|[111]$ (Fig. 4, curve 2) periodic to in-

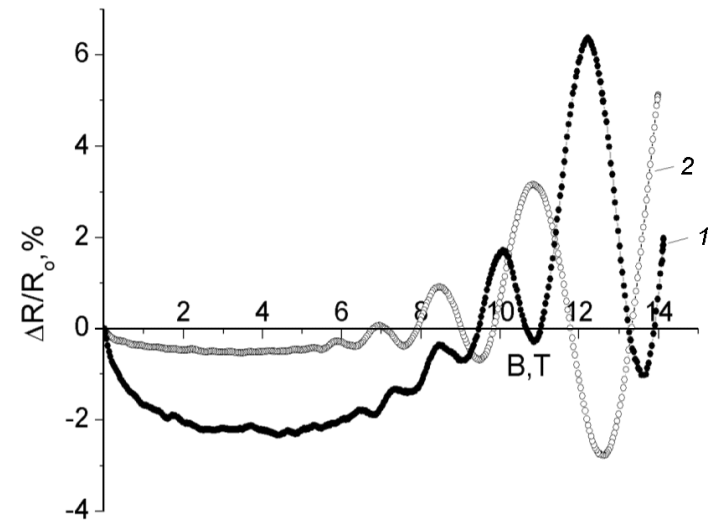

Fig. 4. Magnetoresistance of $n$-type $\mathrm{Ge}$ whiskers with resistivity $\rho_{300 \mathrm{~K}}=$ $0.022 \mathrm{Ohm} \cdot \mathrm{cm}$ under uniaxial compressive strain $\varepsilon=-4.38 \cdot 10^{-3}$ rel.un. at temperature $4.2 \mathrm{~K}$ in the directions: $J\|B\|[111]$ (1), $J\|[111], B\|[110](2)$.

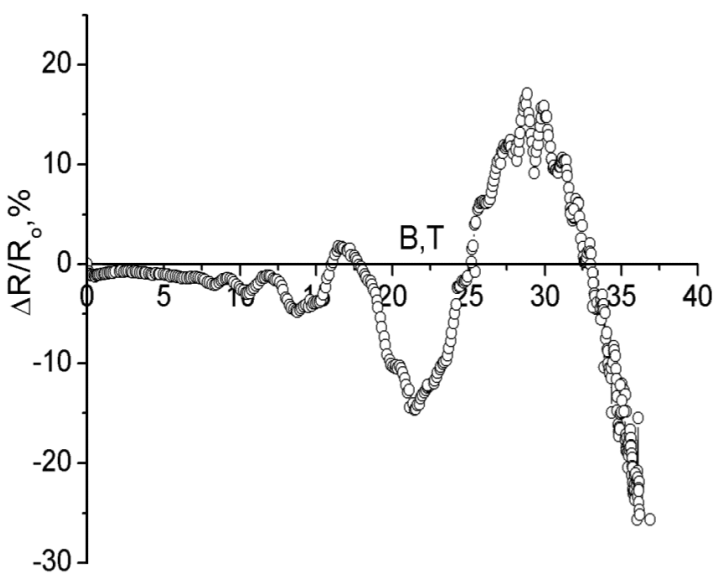

Fig. 5. Magnetoresistance of $n$-type $\mathrm{Ge}$ whiskers with resistivity $\rho_{300 \mathrm{~K}}=$ $0.022 \mathrm{Ohm} \cdot \mathrm{cm}$ in the direction $J\|B\|[111]$ at impulse magnetic fields under uniaxial compressive strain $\varepsilon=-4.38 \cdot 10^{-3}$ rel.un. at temperature $4.2 \mathrm{~K}$.

verse field with a period $\Delta(1 / B)=0.025 \mathrm{~T}^{-1}$, while in the experiment in which $J \|[111]$, $B \|[110]$ oscillation period is $\Delta(1 / B)=$ $0.018 \mathrm{~T}^{-1}$ (Fig. 6).

To interpret obtained results, and for definition and classification of intervalley transitions and also phonons energy, we give energy diagram for $n-G e$ whiskers with resistivity $\rho_{300 \mathrm{~K}}=0.022 \mathrm{Ohm} \cdot \mathrm{cm}$ in a magnetic field derived from the theoretical work [5] (Fig. 7 and Fig. 8). The points marked on the chart identify experimental peaks of magnetophonon oscillations.

On Fig. 4 (curve 1) it is shown that the oscillation maxima of the longitudinal mag- 


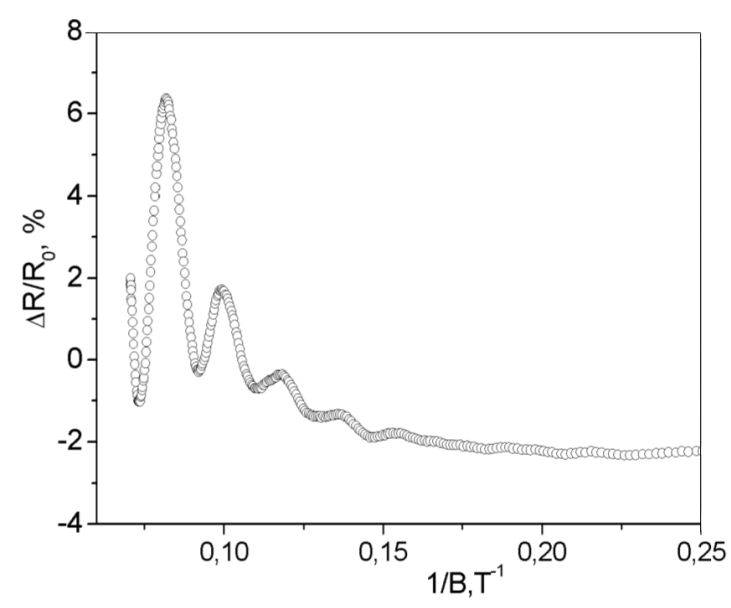

Fig. 6. Magnetoresistance of $n$-type Ge whiskers with resistivity $\rho_{300 \mathrm{~K}}=0.022 \mathrm{Ohm} \cdot \mathrm{cm}$ in the direction $J\|[111], B\|[110]$ at inverse magnetic field under uniaxial compressive strain $\varepsilon=$ $-4.38 \cdot 10^{-3}$ rel.un. at temperature $4.2 \mathrm{~K}$.

netoresistance $J\|[111], B\|[110]$, correspond to the magnetic field of $7 \mathrm{~T}$ and $8.3 \mathrm{~T}$ due to intervalley transitions from the valley with heavy cyclotron effective mass $m_{H}=$ $0.207 m_{e}$ to the valley with light cyclotron effective mass $m_{L}=0.082 m_{e}$ with the participation of the transverse acoustic phonon at the $X$ point of the Brillouin zone with energy $E_{T A}=9.93 \mathrm{meV}$ (Fig. 7, transitions from $N^{\prime}=0$ and $N^{\prime}=1$ to $N=1$, respectively).

Magnetoresistance peaks in the direction $J\|[111], B\|[110]$ for the magnetic field $10 \mathrm{~T}$ and $12 \mathrm{~T}$ correspond to transitions of electrons with the longitudinal optical and longitudinal acoustic phonons in the $X$-point of the Brillouin zone with energy $E_{L o-L A}=$ $29.8 \mathrm{meV}$ (Fig. 7, transitions from at $N^{\prime}=$ 0 and $N^{\prime}=1$ to $N=2$, respectively).

On Fig. 4 (curve 2) detected that the maximum magnetoresistance oscillation is in the direction $J\|B\|[111]$, which corresponds to the magnetic field of $6.5 \mathrm{~T}$ is due to intervalley transfer of electrons from the valley with heavy cyclotron effective mass $m_{H}=0.207 m_{l}$ to the valley of easy cyclotron effective mass $m_{L}=0.082 m_{e}$ with transverse of the acoustic phonon at the $X$ point of the Brillouin zone with energy $E_{T A}$ $=9.93 \mathrm{meV}$ (Fig. 8, transition from $N^{\prime}=0$ at $N=1$ ).

Magnetoresistance peaks in the direction $J\|B\|[111]$ for the magnetic field $17.5 \mathrm{~T}, 9 \mathrm{~T}$ and $7.5 \mathrm{~T}$ correspond to intervalley transitions of electrons from the valley with heavy cyclotron mass to the valley with light cyclotron effective mass with the use

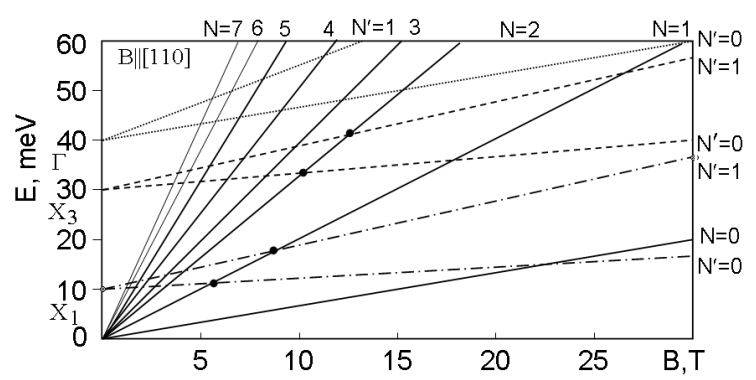

Fig. 7. Energy diagram of $n$-type Ge whiskers with resistivity $\rho_{300 \mathrm{~K}}=0.022 \mathrm{Ohm} \cdot \mathrm{cm}$ at magnetic field with the direction $J \|[111]$, $B \|[110]$ under uniaxial compressive strain $\varepsilon=$ $-4.38 \cdot 10^{-3}$ rel.un. at temperature $4.2 \mathrm{~K}$. Founded experimental peaks of magnetophonon oscillations are marked by the points on the diagram.

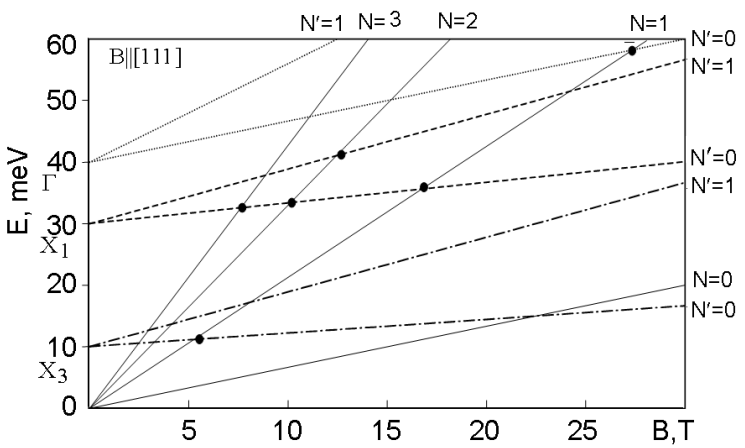

Fig. 8. Energy diagram of $n$-type $\mathrm{Ge}$ whiskers with resistivity $\rho_{300 \mathrm{~K}}=0.022 \mathrm{Ohm} \cdot \mathrm{cm}$ at magnetic field with the direction $J\|B\|[111]$ under uniaxial compressive strain $\varepsilon=-4.38 \cdot 10^{-3}$ rel.un. at temperature $4.2 \mathrm{~K}$. Founded experimental peaks of magnetophonon oscillations are marked by the points on the diagram.

of longitudinal optical phonons at the $X$ point of the Brillouin zone with the energy of an optical phonon $E_{L o}=29.8 \mathrm{meV}$ (Fig. 8, transitions from $N^{\prime}=0$ to $N=1, N=2$ and $N=3$, respectively). A maximum at the induction of $28 \mathrm{~T}$ due to intervalley transition of electrons with the longitudinal optical phonons in the $G$-point of the Brillouin zone with energy $E_{T A}=37.3 \mathrm{meV}$ (Fig. 8, the transition from $N^{\prime}=0 N=1$ ).

An interesting feature of the detected transitions is a limited temperature range of their appearance. Fig. 9 and Fig. 10 show temperature influence on the behaviour of the magnetoresistance of the same whiskers under tensile and compressive strain respectively.

From the temperature dependences of the magnetoresistance in the direction $J \|[111]$, $B \perp[111]$ shown on the Fig. 9 for $n-G e$ 


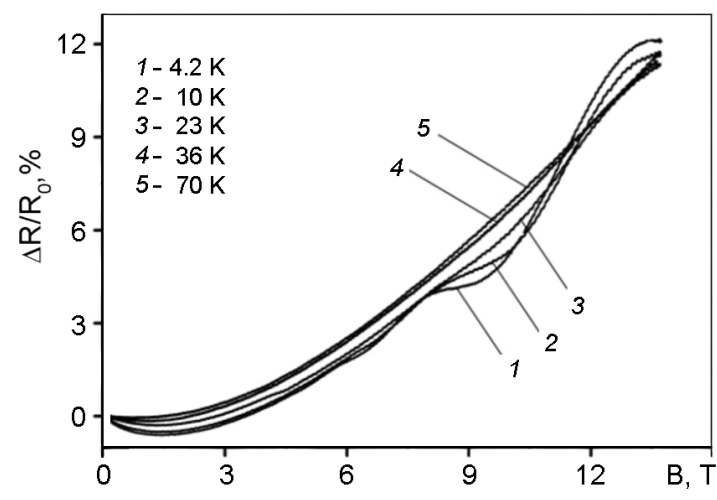

Fig. 9. Temperature dependences of magnetoresistance in direction $J \|[111], B \perp[111]$ for $n$-type $G e$ whiskers with resistivity $\rho_{300 \mathrm{~K}}=$ $0.02 \mathrm{Ohm} \cdot \mathrm{cm}$ under uniaxial tensile strain $\varepsilon=$ $1.37 \cdot 10^{-3}$ rel.un. at different temperatures, $\mathrm{K}: 4.2(1), 23(2), 36(3), 50(4)$.

whiskers with a resistivity $\rho_{300 \mathrm{~K}}=$ $0.02 \mathrm{Ohm} \cdot \mathrm{cm}$ under tensile strain, it is clear that the maximum amplitude of the oscillating peaks at $4.2 \mathrm{~K}$, and the period of oscillations of the magnetoresistance is independent of temperature. As shown in Fig. 9, with increasing temperature the peak value decreases and at the temperature $36 \mathrm{~K}$ curve is monotonic (curve 3 on Fig. 9). As shown on Fig. 10 for the magnetoresistance in the direction $J\|B\|[111]$, the largest amplitude of the oscillating peaks detected at temperature $4.2 \mathrm{~K}$ with increasing temperature to $35 \mathrm{~K}$ observed their practical attenuation.

The relatively low temperature range of scattering by acoustic and even optical phonons related, on our opinion, with the influence of strain on the properties of heavily doped whiskers near metal-insulator-transition. A similar behaviour we observed earlier during the study piezo-termo EMF in heavily doped Si-Ge whiskers, for which was shown a sharp increase in the Seebeck coefficient at the imposition of strain in the temperature range $4.2 \mathrm{~K}-20 \mathrm{~K}$, which was associated with the capture of carriers by phonons [20].

These experimental results can be used to create sensors of mechanical and thermal values based on $n-G e$ whiskers, in which there is a weak dependence of resistance on magnetic field. As shown by studies, best for low-temperature strain - temperature sensors are $n-G e$ whiskers with resistivity of $0.02 \mathrm{Ohm} \cdot \mathrm{cm}$. Calibration characteristic of the sensor is shown on Fig. 11. Minimal change in resistance in these samples at $4.2 \mathrm{~K}$ observed in a transverse magnetic

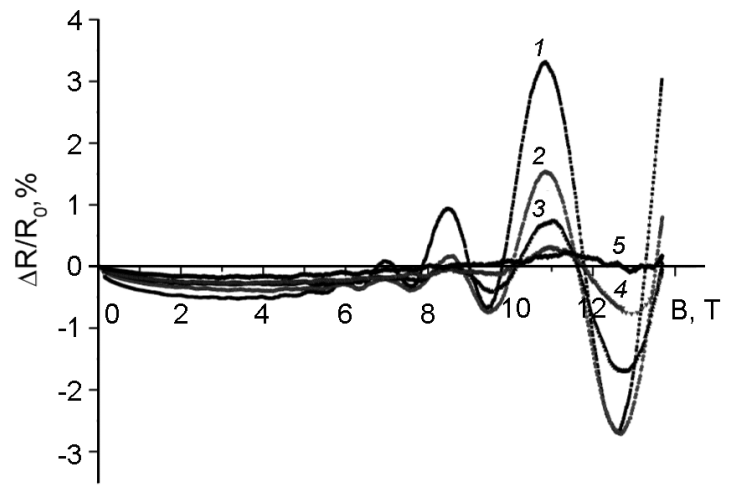

Fig. 10. Temperature dependences of magnetoresistance in direction $J\|B\|[111]$ for $n$-type Ge whiskers with resistivity $\rho_{300 \mathrm{~K}}=$ $0.02 \mathrm{Ohm} \cdot \mathrm{cm}$ under uniaxial compressive strain $\varepsilon=4.38 \cdot 10^{-3}$ rel.un. at different temperatures, K: 4.2 (1), 12 (2), 22 (3), 35 (4), $54(5)$.

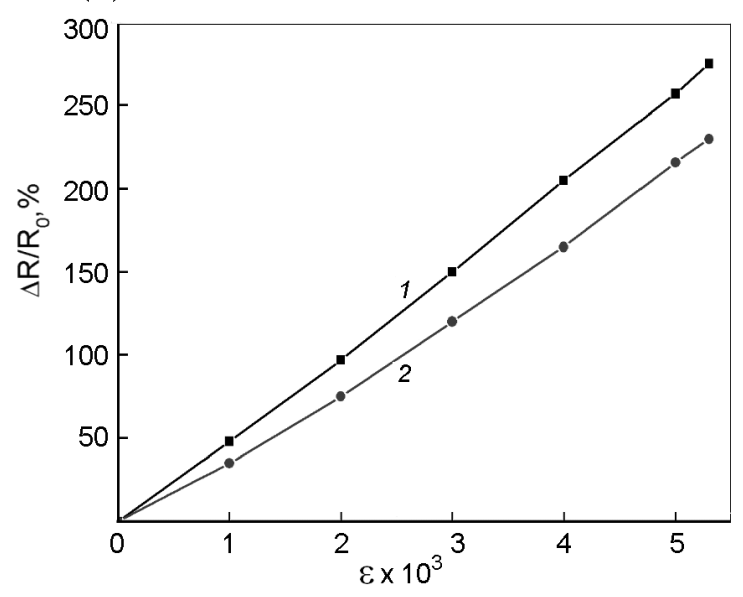

Fig. 11. Graduating characteristic for sensitive element of the strain-temperature sensor based on the $n-G e$ whiskers with resistivity $\rho_{300 \mathrm{~K}}=0.02 \mathrm{Ohm} \cdot \mathrm{cm}$.

field. Thus, the compressive strain magnetoresistance is almost independent from the magnetic field in the range 0-14 $\mathrm{T}$ (Fig. 2, curve 3), and for tensile strain - in the range of $0-5 \mathrm{~T}$ (Fig. 2, curve 2). At higher fields up to $14 \mathrm{~T}$ in tensile strain samples revealed almost linear magnetoresistance change with an increase of $1 \% / T$, and this dependence varies slightly with temperature in the range $20-70 \mathrm{~K}$ (Fig. 9, curves 3-5). The precision of strain measurement is about $10^{-5}$, and temperature $- \pm 0.1 \mathrm{~K}$.

\section{Conclusions}

Magnetophonon oscillations of the magnetoresistance in $n$-type conductivity $\mathrm{Ge}$ whiskers with the concentration of impurities $\mathrm{Sb}$, corresponding to metal-insulator 
transition in the temperature range 4.2$30 \mathrm{~K}$ were found. Magnetoresistance oscillations in the direction $(J \| B \perp[111])$ observed in the samples doped to concentrations near the MJT with a metal part in the unstrained whiskers with $\rho_{300 \mathrm{~K}}=$ $0.01 \mathrm{Ohm} \cdot \mathrm{cm}$. When approaching the metalinsulator transition $\quad\left(\rho_{300 \mathrm{~K}}=0.02-\right.$ $0.022 \mathrm{Ohm} \cdot \mathrm{cm}$ ) oscillations are stimulated by relative strain $\varepsilon=1.37 \cdot 10^{-3}$. On the basis of determining the period of oscillating peaks in the reciprocal field $\Delta(1 / B) \approx 0.04 \mathrm{~T}^{-1}$, based on the geometry of the experiment showed that the detected magnetophonon oscillations peaks occur due to transitions between Landau levels in the valley of the effective mass $m_{L}=0.082 m_{e}$ with the transverse optical phonon in the $L$-point of the Brillouin zone with energy $E_{T O} \approx 36.15 \mathrm{meV}$.

Magnetophonon oscillations of magnetoresistance are observed in the samples with $\rho_{300 \mathrm{~K}}=0.02-0.022 \mathrm{Ohm} \cdot \mathrm{cm}$ doped to concentrations in the vicinity to MIT from the dielectric side under compressive strain.

Identified oscillation peaks of magnetoresistance are periodic to inverse field with a period $\Delta(1 / B)=0.025 \mathrm{~T}^{-1}$ in the geometry of the experiment $J\|B\|[111]$, where as oscillation period is $\Delta(1 / B)=0.018 \mathrm{~T}^{-1}$ in the geometry of the experiment $J \|[111]$, $B \|[110]$. The identified resonant oscillations are caused by intervalley scattering of electrons, including their interband transitions between Landau levels of the valley with heavy cyclotron effective mass $m_{H}=$ $0.082 m_{e}$ to the valley with light cyclotron effective mass $m_{L}=0.207 m_{e}$ with acoustic and optical phonons in $\Gamma, X_{1}$ and $X_{3}-$ points of the Brillouin zone with energy $E_{T A}=37.3 \mathrm{meV}, \quad E_{T A}=9.93 \mathrm{meV}$ and $E_{L O}=29.8 \mathrm{meV}$, respectively.

As shown the experimental studies, the value and sign of the uniaxial mechanical strain, magnetic field and temperature are critical factors due to which we can control the amplitude mahnetofonon oscillations. Limited temperature range $(4.2-30 \mathrm{~K})$ observation of magnetophonon oscillations in
$n-\mathrm{Ge}$ whiskers are probably due to the influence of strain on the properties of heavily doped whiskers near MIT.

On the base of investigated $n-G e$ whiskers with $\rho_{300 \mathrm{~K}}=0.02 \mathrm{Ohm} \cdot \mathrm{cm}$ there were created strain-temperature sensors with minimal sensitivity to the influence of magnetic field. The precision of strain measurement is about $10^{-5}$, and temperature $- \pm 0.1 \mathrm{~K}$.

\section{References}

1. Y.Hirose, T.Tsukahara, C.Hamaguchi, $J$. Phys. Soc. Jap., 52, 4291 (1983).

2. C.Hamaguchi, Y.Hirose, K.Shimomae, Lecture Notes in Phys., 177, 423 (1983).

3. H.Futagawa, N.Miura, K.Yamada et al., J. Phys. Soc. Jap., 62, 4407 (1993).

4. N.Kamata, H.Futagawa, K.Yamada et al., Semicond.Sci. Technol., 7, 639 (1992).

5. S.Chil Lee, J.Yon Kim, D.Chul Kim, D.Lak Kimy et al., J. Korean Phys. Soc., 32, 138 (1998).

6. D.Schneider, C.Brink, G.Irmer et al., Phys. B: Phys. Condens. Matter., 256, 625 (1998).

7. C.Faugeras, D.K.Maude, G.Martinez et al., Phys.Rev. B, 69, 673405 (2004).

8. D.Shik Kang, S.Chil Lee, S.Whan Kim, J. Korean Phys. Soc., 57, 760 (2010).

9. N.Miura, N.V.Kozlova, K.Dorr et al., J. Low Temper. Phys., 159, 222 (2010).

10. G.Tomaka, E.M.Sheregii, J.Cebulski et al., Proc. SPIE, 4413, 248 (2000).

11. Y.Kim, J.M.Poumirol, A.Lombardo et al., Condens. Matter., 1211, 6094 (2012).

12. O.Kashuba, V.I.Fal'ko, Phys.Rev.B, 87, 161404 (2013).

13. O.Kashuba, V.I.Fal'ko, New J. Phys., 14, 105016 (2012).

14. A.I.Klimovskaya, I.V.Prokopenko, S.V.Svechnikov et al., Mater. Sci. and Engin., C19, 205 (2002).

15. E.G.Gule, G.Yu.Rudko, A.I.Klimovskaya et al., Phys.Stat. Solidi B, 161, 565 (1997).

16. A.A.Druzhinin, I.I.Maryamova, I.V.Pavlovskiy et al., Visnyk of Lvivska Polytech. Nation. Univ. Electron., 532, 112 (2005).

17. A.Druzhinin, I.Hortynska, I.Maryamova et al., Proc. SPIE, 4413, 143 (2001).

18. R.T.Payne, Phys. Rev., 139, A570 (1965).

19. A.N.Voronovski, E.M.Dizhur, E.S.ltskevich, Zh.Eksp.Teor.Fiz., 77, 1119 (1979).

20. A.A.Druzhinin, I.P.Ostrovskiy, N.S.Liach et al., J.Phys. Invest., 9, 71 (2005). 